\title{
Reeducaçáo da Postura com a Equoterapia
}

\author{
Reeducation of Posture with Hippotheraphy
}

\section{Michele Marinho da Silveira', Lia Mara Wibelinger ${ }^{2}$}

\section{RESUMO}

\begin{abstract}
A Equoterapia emprega técnicas de equitação e atividades equestres que proporcionam ao praticante benefícios físicos, psicológicos, educacionais e sociais exigindo a participação de todo o corpo, contribuindo para o desenvolvimento do equilíbrio, tônus, força muscular, conscientizaçáo corporal, alinhamento postural, aperfeiçoamento da coordenação motora, atenção, auto-confiança e auto-estima. Objetivo. verificar os efeitos da Equoterapia na reeducação da postura enfatizando a interação do cavalo usado de forma terapêutica em indivíduos com escoliose e cifose. Método. Neste estudo de revisão de literatura foram utilizados os artigos da base de dados Pubmed, empregandose as seguintes palavras-chave: Hippotherapy and posture. Também, foram usadas monografias, livros de ortopedia, pediatria e Equoterapia, bibliografias do período de 1978 a 2009. Resultados. A Equoterapia como um recurso terapêutico mostrou ser importante para o tratamento das alteraçóes posturais. Conclusão. A detecção precoce desses distúrbios posturais permite aos fisioterapeutas avaliarem objetivamente os prejuízos funcionais e traçar metas para a reeducação da postura, pois o tratamento das alterações posturais com o cavalo oferecerá situaçóes de ortostatismo de tronco, buscando a estimulação mais correta do equilíbrio, a conscientização e correção postural.
\end{abstract}

Unitermos. Equoterapia, Postura, Tratamento.

Citaçáo. Silveira MM, Wibelinger LM. Reeducação da Postura com a Equoterapia.

\begin{abstract}
Hippotherapy employs techniques of riding and equestrian activities that provide benefits to the practitioner physical, psychological, educational and social demands the participation of the whole body, contributing to the development of equilibrium, muscle tone, muscle strength, body awareness, postural alignment, improving coordination motor, attention, self-confidence and self esteem. Objective. To assess the effects of equine therapy in rehabilitation of posture emphasizing the interaction of horse used therapeutically in patients with scoliosis and kyphosis. Method. In this literature review were used articles from PubMed database, using the following keywords: hippotherapy and posture. Also, were used monographs, books of orthopedics, pediatrics and hippotherapy, bibliographies of the period from 1978 to 2009. Results. Hippotherapy as a therapeutic resource was important for the treatment of postural changes. Conclusion. Early detection of these disorders posture allows physiotherapists to assess objectively the functional impairment and set goals for the rehabilitation of posture, as the treatment of postural changes with the horse standing offer situations trunk, trying to stimulate more correct equilibrium, awareness and posture correction.
\end{abstract}

Keywords. Hippotherapy, Posture, Treatment.

Citation. Silveira MM, Wibelinger LM. Reeducation of Posture with Hippotheraphy.
Trabalho realizado no Colégio Brasileiro de Estudos Sistêmicos, Porto Alegre-RS, Brasil.

1. Fisioterapeuta, Mestranda bolsista Capes do Programa de Pós-Graduação em Envelhecimento Humano da Universidade de Passo Fundo, Passo FundoRS, Brasil.

2. Fisioterapeuta, Mestre e Doutoranda em Gerontologia Biomédica pela PUC/RS, Docente da Faculdade de Fisioterapia da Universidade de Passo Fundo, Passo Fundo-RS, Brasil.
Endereço para correspondência: Michele M Silveira Rua Palmeira, 20/803 CEP 99040-460, Passo Fundo-RS, Brasil. E-mail: mm.silveira@yahoo.com.br 


\section{INTRODUÇÃO}

A Equoterapia, por ser uma área nova no país, deve dedicar-se à investigação científica. Acredita-se que, se comprovado cientificamente seus benefícios, pode-se introduzir a Equoterapia na ortopedia e traumatologia como mais uma área a ser explorada, beneficiando as pessoas de forma inovadora e prazerosa, náo limitando a atendimentos em clínicas e salas fechadas, que nem sempre são estímulos para os pacientes que estão há longo tempo em tratamento ${ }^{1}$.

O tratamento das alteraçóes posturais com a Equoterapia promove reeducação e reabilitação motora e mental, através da prática de atividades equestres e técnicas de equitação através do uso do cavalo como instrumento cinesioterapêutico. É possível utilizar as ações do cavalo e o comportamento intencional da criança para desenvolver reaçóes de orientação, melhorar os tempos de reação e atenção, potencializar a capacidade executiva e a discriminação espacial em relação à direção, distância, sequencialidade, alinhamento postural e lateralidade ${ }^{2}$.

O alinhamento corporal está associado ao ajuste tônico e a organização biomecânica com o deslocamento do centro gravitacionário pelo movimento tridimensional do cavalo. Com isso ocorre estímulo do aparelho vestibular, que ativa a musculatura de sustentaçâo da cabeça e tronco. Os estímulos articulares de pressão, somatossensorial e visual também contribuem para o ajuste tônico adequado. Com o ajuste postural há uma estabilização da cintura escapular e membros superiores, possibilitando movimentos mais seletivos, controlados e harmônicos, maior estabilidade e funcionalidade, a alternância de movimentos de braços e dissociação de cinturas. Os ajustes posturais podem auxiliar na correção postural do praticante, prevenindo, reeducando ou minimizando as alteraçóes posturais ${ }^{3}$.

A escoliose e cifose se desenvolvem principalmente nas fases de crescimento e devem ser tratadas precocemente. A escoliose é um desvio lateral não fisiológico da coluna vertebral. Devido ao alinhamento vertebral e às relaçóes estruturais das bordas vertebrais e às articulaçóes posteriores, a inclinação lateral é acompanhada por rotação simultânea ${ }^{4}$. E a cifose, é considerada um desvio ântero-posterior da coluna vertebral, caracterizada por curvatura torácica aumentada, protração escapular e rotação de cabeça, sendo ambas causadoras de má postura e devem ser tratadas para evitar futuras deformidades na coluna vertebral ${ }^{5}$.

Dessa forma, sendo a escoliose e a cifose alteraçôes posturais que causam desvios na coluna vertebral e a Equoterapia um tratamento que visa estabilidade postural e alinhamento com o centro de gravidade, este estudo teve como objetivo realizar uma revisão de literatura na base de dados do Pubmed, livros para o conhecimento da Equoterapia, verificando seus efeitos na coluna vertebral de crianças e adolescentes que apresentam alteraçóes em sua postura visando o aperfeiçoamento desta postura através da prática e do trabalho de reabilitação de pacientes com estas alteraçôes posturais.

\section{MÉTODO}

Neste estudo de revisão de literatura, foram realizadas pesquisas nas bases de dados do Pubmed com as seguintes palavras-chave: hippotherapy and posture. Foram incluídos todos os artigos relatando a reabilitação com Equoterapia. Também, foram utilizados livros de ortopedia, pediatria e Equoterapia no período de 1978 a 2009.

\section{RESULTADOS}

A partir destas palavras-chave foram encontrados sete artigos que relatam estudos sobre a reabilitaçáo com Equoterapia. Como resultados encontrados destacamse sete estudos que relatam resultados positivos na reabilitação com Equoterapia, observando-se a melhora do equilíbrio, da postura, da coordenação, da marcha e de ganhos motores $^{6-9}$; aumento da estabilidade sobre o cava$1 \mathrm{o}^{10}$; melhora do funcionamento articular do quadril ${ }^{11}$; e um estudo que observou-se não haver ganho em qualquer uma das medidas do resultado padronizado, mas frente à percepção dos pais as crianças tiveram melhorias na amplitude de movimento e controle da cabeça ${ }^{12}$.

\section{DISCUSSÃO}

\section{Alteraçóes Posturais}

As alterações posturais são mais marcantes na adolescência. No entanto, são alterações fisiológicas que ocorrem devido ao crescimento simultâneo, não proporcional ao do sistema músculo esquelético. $\mathrm{O}$ crescimento músculo-esquelético pode ser um aliado importante no tratamento das alteraçóes posturais ${ }^{13}$. 
A adolescência é o período das mais dramáticas alteraçóes no crescimento e das transformações. Há aceleração do peso e crescimento linear. Durante o estirão de crescimento na adolescência, as jovens têm um incremento médio na altura de $8 \mathrm{~cm} /$ ano à idade média de 12 anos, enquanto o estirão de crescimento masculino, à idade média de 14 anos, é de $10 \mathrm{~cm} /$ ano, em média. Há um padrão ordenado de progressão do crescimento do esqueleto das partes distais para as proximais do corpo ${ }^{14}$.

Somente $10 \%$ da população corresponde aos indivíduos com postura correta e que quase nunca apresentam dores. Mais de $90 \%$ dos indivíduos apresentam um desequilíbrio postural ${ }^{15}$.

O equilíbrio correto da coluna vertebral e a postura são pré-requisitos para o uso eficiente das extremidades. Os desvios posturais, como a posição da cabeça para frente causando uma cifose dorsal, também a lordose lombar e até mesmo a escoliose, podem acarretar em consequências sobre as articulaçóes do ombro, temporomandibular, quadris, joelhos e pés ${ }^{16}$.

Um dos pontos-chave dentro das técnicas empregadas no tratamento da escoliose e da cifose é a tomada de consciência do corpo, o que possibilitará a realização das correçôes efetivas. No relaxamento, são básicos o controle e a conscientização do esquema corporal, o paciente fará os exercícios corretivos dentro de um programa sem tensão, e com a percepção máxima da musculatura que atua em cada momento ${ }^{17}$.

\section{Equoterapia}

A Equoterapia pode ser considerada como um conjunto de técnicas reeducativas que agem para superar danos sensoriais, motores, cognitivos e comportamentais, através de uma atividade lúdico-desportiva, que tem como meio o cavalo ${ }^{18}$.

O cavalo quando anda, serve como meio terapêutico por transmitir os movimentos ao cavaleiro. Com o praticante na posição sentada, os reflexos posturais são proporcionados pelos específicos movimentos do cavalo ao andar em linha reta ou curva. Delicadas respostas coordenadas são exigidas e o exercício postural e as reações de equilíbrio acontecem. Estimulações proprioceptivas e sensório-motoras incrementam as atitudes posturais, facilitam os sentidos, os relaxamentos musculares e me- lhoram os padróes de movimento de todo o corpo do praticante. Ao mesmo tempo, movimentos de correçáo postural treinam a musculatura ao regular as atividades sinérgicas e por regularem o tônus muscular. Além disso, provocam movimentos suaves e harmônicos nas articulaçôes e tendóes musculares ${ }^{19}$.

Segundo um evento desenvolvido pela Associação Gaúcha de Equoterapia, em 2006, a Equoterapia é composta por quatro fases de atuação: hipoterapia, equitação terapêutica, pré-esportiva e hipismo adaptado, destas, a mais indicada para ser utilizada em um trabalho de reabilitação e reeducação onde trabalhará o praticante de forma global é a hipoterapia, pois é um método aplicado principalmente por fisioterapeutas, com o cavalo ao passo. A montaria geralmente é dupla e em sela especial, o guia é extremamente necessário e para montar e apear o praticante do cavalo utiliza uma rampa.

Existem movimentos progressivos ou de avanço que são os diversos modos de progressão do cavalo: o passo, o trote e o galope. O trote e o galope são andaduras saltadas. Isto quer dizer que entre um lance e outro, seja de trote ou de galope, o cavalo executa um salto, a um tempo de suspensão, em que ele náo toca com seus membros no solo. Seus movimentos mais rápidos e mais bruscos e quando ele retorna ao solo exige do cavaleiro mais força para se segurar e um maior desenvolvimento ginástico para poder acompanhar os movimentos do animal. Por isso, estas andaduras só podem ser usadas em Equoterapia, com praticantes em estágio mais avançados, pois o passo é a andadura mais recomendada para o tratamento de Equoterapia ${ }^{3}$.

Com o cavalo ao passo, o praticante sofrerá uma série de estímulos mecânicos. $\mathrm{O}$ passo do cavalo, sendo uma andadura a quatro tempos e em diagonais, enviará estímulos a quem está montando, que corresponderão com uma diferença mínima de 5\% ao caminhar humano. Os movimentos e respostas equilibratórias que o cavaleiro deverá executar para manter-se sobre o cavalo são os mesmos necessários para a marcha humana, partindo-se da pelve, tronco, membros superiores e cabeça. À pelve deve ser dada especial atenção, pois a maioria das pessoas tem toda a sua postura alterada em função de um mau posicionamento pélvico. À cavalo, ocorre uma reeducaçâo desta postura de forma dinâmica, o que é ideal, pois 
somos seres dinâmicos e não estáticos de acordo com um evento desenvolvido pela Associação Gaúcha de Equoterapia em 2006.

Os objetivos da Equoterapia são muitos, entre eles pode-se melhorar o conhecimento do esquema corporal; melhorar a postura como um todo, normalizar o tônus corporal; estimular o equilíbrio; melhorar a coordenaçẫo espaço-temporal; educar o sistema nervoso sensorial, manter articulaçóes íntegras e dentro da normalidade; realizar reeducação respiratória; introduzir movimentos e posturas inibidores dos reflexos; relaxamento; desenvolver motivação, autoconfiança e auto-valorização, que são de extrema importância para o sucesso dos objetivos citados acima ${ }^{2}$.

A Equoterapia é indicada nos casos de deficiências motoras causadas por lesôes neuromotoras, traumas encefálicos, sequelas de processos inflamatórios do SNC, déficit de produção de movimento; distúrbios da coordenação e da regulação do tônus muscular, como a espasticidade, distonias, distúrbios de equilíbrio e déficit neuromotores por lesões da medula espinhal; lesóes de nervos periféricos (paralisias obstétricas do plexo braquial); distúrbios evolutivos e comportamentais; distúrbios sensoriais; doenças ortopédicas ${ }^{20}$.

$\mathrm{Na}$ coluna vertebral apresentam-se as seguintes contra-indicaçóes como os estados pós-cirúrgicos da coluna vertebral (8 meses antes ou 12 meses após a cirurgia ou quando o médico informar que uma sólida fusão óssea já ocorreu e que o cavalgar poderá ser iniciado); em cirurgias com resultados instáveis; processo inflamatório da coluna, em seus discos intervertebrais ou quando os processos piorarem; dor ou perda sensitiva que aumentem ao cavalgar; processos degenerativos moderados ou graves; fraturas ósseas patológicas; deformidades congênitas, anormalidades de fusóes ósseas por processo inflamatório, instabilidade ou degeneração da coluna; osteoporose moderada ou grave; osteogênese imperfeita; doença de Scheuermann com processo inflamatório; escoliose maior que 30-40 graus, lordose estrutural e cifose moderada ou grave; espondilolistese; instabilidade da coluna cervical atlanto-axial ${ }^{21}$.

Os efeitos terapêuticos que podem ser alcançados são: Melhoramento da relação com a valorização plena do indivíduo a cavalo (comunicação, autocontrole, auto- confiança, atenção); melhoramento da psicomotricidade com a melhora do tônus (mobilização das articulaçóes da coluna e do quadril, facilitamento do equilíbrio e da postura do tronco ereto, favorecimento da obtenção de lateralidade, melhora da percepção do esquema corporal; favorece a referência de espaço e de tempo, permite que se trabalhe a coordenação e dissociação de movimentos, facilita a precisão do gesto, permite melhor conhecimento de posiçóes de seu corpo e do corpo do cavalo, permite a integração do gesto para compreensão de uma ordem recebida ou por imitação); melhoramento de natureza técnica (facilitando as aprendizagens de cuidados com os cavalos, facilitando o aprendizado das técnicas de equitação, como condução do animal em várias velocidades, manejo e até pequenos saltos, para alguns praticantes); e melhoramento da socialização (integração de indivíduos com danos cognitivos ou corporais com os demais praticantes e com a equipe multidisciplinar) ${ }^{22}$.

Em uma equipe técnica multidisciplinar de Equoterapia, o Fisioterapeuta apresenta as importantes funçóes como avaliar e elaborar o diagnóstico fisioterapêutico do praticante; avaliar a potencialidade físico-funcional, detectando alteraçóes presentes; orientar a equipe em relação aos cuidados e contra indicaçóes do método com cada praticante; prescrever técnicas e condutas fisioterapêuticas com objetivos a curto, médio e longo prazo, esclarecer dúvidas e orientar a equipe técnica em relação às alteraçóes motoras dos praticantes e realizar sistematicamente reavaliaçóes dos praticantes.

\section{Equoterapia nas Alteraçóes Posturais}

O relaxamento é indicado para os trabalhos de correção postural a partir da conscientização corporal que ele proporciona, podendo ser realizado com o praticante em decúbito dorsal ou ventral sobre a garupa do cavalo, sempre em ambiente calmo. A partir do passo do cavalo, tanto em decúbito ventral como em decúbito dorsal e com um bom apoio, pode-se ganhar muito com a conscientização que o praticante consiga ter do movimento das estruturas do cavalo sob seu corpo, atuando em forma de massagem de baixo para cima em sua musculatura dorsal ${ }^{1}$.

Em um estudo realizado com dez crianças entre seis e doze anos, com diagnóstico de paralisia cerebral, apresentando alteração postural (escoliose acima ou igual a 5 
graus), espasticidade leve a moderada, marcha independente e boa compreensão, foi realizado um programa de equoterapia, com duração de 4 meses, 2 vezes por semana, com sessôes de 30 minutos, resultando na diminuição do grau de escoliose e na melhora dos parâmetros psicomotores (modulação tônica, mobilidade do tronco e membros superiores, coordenação dos movimentos, equilíbrio, postura, marcha) e psicossociais (auto-confiança, auto-estima, motivação, atenção e concentração, autonomia e iniciativa). $\mathrm{O}$ autor refere que durante as sessóes foram corrigidas as posturas, de forma que o cavaleiro estivesse bem posicionado e confortável para se sentir seguro ${ }^{23}$.

Uma paciente com cifose dorsal moderada e comprometimento do aparelho respiratório realizou tratamento com Equoterapia e em 3 meses de tratamento (27 sessóes), foi avaliada observando que houve uma melhora da postura, com ombros mais alinhados, pescoço ao longo do tronco bem menos anteriorizado, postura mais ereta, respiração menos ofegante e melhora da auto-estima ${ }^{24}$.

Outra população estudada, composta por 30 crianças de uma Escola de Ensino Fundamental, localizada em Estância Velha, sendo 14 do sexo masculino e 16 do sexo feminino, todas com diagnóstico de escoliose, praticaram Equoterapia duas vezes por semana, separados em dois grupos, com atendimento em média de uma hora cada grupo, no período de agosto de 2002 a maio de 2003, dez meses de tratamento. Após a análise das informaçóes foi observado que os resultados do trabalho foram positivos quanto à diminuição dos desvios laterais da coluna vertebral encontrada nos escolares, tendo uma relevância científica social ${ }^{1}$.

Em um estudo sobre o tratamento com Equoterapia em 4 crianças entre 5 e 9 anos com deficiências físicas e atrasos motores, as crianças tiveram resultados estatisticamente significativos após 6 meses de intervenção no quesito funcionalidade, melhorando o equilíbrio, postura, coordenação e tendo ganhos motores ${ }^{6}$.

Em uma pesquisa avaliou-se as mudanças na magnitude e distribuição da pressão de contato entre o cavaleiro e o cavalo durante uma série de aulas terapêuticas de equoterapia (5 aulas de 20 minutos em 3 semanas) com mulheres saudáveis apresentou com a crescente experiência dos participantes, um aumento na pressão no contato de seu corpo e o dorso do cavalo, e também na estabilida- de do movimento ${ }^{10}$.

Foram avaliadas a função motora de 3 crianças entre 27-54 meses, com paralisia cerebral, aplicando a equoterapia uma vez por semana durante 10 semanas e verificando a percepção dos pais frente a isso através de questionários, sendo que nenhuma das crianças apresentou ganhos em qualquer uma das medidas do resultado padronizado, mas as percepçôes dos pais foram muito positivas, com melhorias relatadas na amplitude de movimento e controle da cabeça ${ }^{12}$.

Foi verificado se a Equoterapia tem aspectos positivos e os efeitos de curto prazo na marcha e no controle postural de pessoas com deficiências motoras. Foi aplicado em 21 crianças e adolescentes, com séries de oito semanas de equitação terapêutica, ao final os indivíduos não melhoram o controle postural e tiveram apenas um pequeno efeito positivo sobre o desempenho da marcha ${ }^{7}$.

Em estudo com 10 mulheres com diagnóstico de coxoartrose, realizaram equoterapia durante 3 meses, 3 vezes por semana, sendo que a equoterapia melhorou o estado de conjunto funcional do quadril em pacientes com coxoartrose; melhorou o componente músculo-tendínea do movimento da articulação do quadril podendo ser considerada como o método de tratamento de patogenético coxartrose ${ }^{11}$.

A criança pode ser motivada a cooperação satisfatória e aceita o cavalo como seu amigo, sendo que foi encontrado como resultado da equoterapia para 27 crianças afetadas com paralisia cerebral, melhora no tônus da postura, na inibição dos padróes de movimento patológico, facilitação de reaçóes normais automáticas e a promoção da percepção sensório-motor é atingida ${ }^{8}$.

Em outra pesquisa de reabilitação com Equoterapia durante um ano realizado em quatro crianças com deficiência física, entre 5 e 9 anos, avaliou-se os resultados funcionais usando a Goal Attainment Scale (GAS) tendo como resultado que três das quatro crianças tiveram uma melhora significativa nos resultados funcionais ao final de um ano de tratamento e duas das quatro crianças tiveram resultados estatisticamente significativos após 6 meses de intervenção com Equoterapia?.

Em adição, alguns autores relatam que a Equoterapia tem se tornado uma importante opção terapêutica em pacientes que sofrem de disfunção motora. A base 
fisiológica dessa abordagem é a transmissão tridimensional do movimento do cavalo no corpo do paciente. Estes estímulos de movimento são utilizados para exercer efeitos positivos sobre o controle postural e marcha dos pacientes ${ }^{7}$.

Observou-se que a Equoterapia foi eficaz na maior parte dos estudos, sendo de grande importância que novas pesquisas sejam realizadas para que se possa ter mais resultados e comprovaçóes científicas de que este método terapêutico ajuda a melhorar a vida das pessoas e a contribuir para ganhos nos aspectos físicos e emocionais, sendo o cavalo um agente e mediador cinesioterapêutico para estes pacientes.

\section{CONCLUSÃO}

A detecção precoce desses distúrbios posturais permite aos fisioterapeutas avaliarem objetivamente os prejuízos funcionais e traçar metas para a reeducação da postura, pois o tratamento das alteraçóes posturais com o cavalo oferecerá situaçóes de ortostatismo de tronco, buscando a estimulação mais correta do equilíbrio, a conscientização e correção postural. Nas pesquisas encontradas com postura e equoterapia obtiveram-se melhoras significativas de reeducação postural, mas em outros estudos com crianças com deficiências motoras a melhora não foi tão observada. Verificou-se, também, que há uma escassez de material, sugerindo que mais pesquisas sejam realizadas com Equoterapia e postura a fim de que se possam ter mais resultados cientificamente comprovados.

\section{REFERÊNCIAS}

1.Santos RA Aplicação das Técnicas de Equoterapia e os Desvios Posturais Laterais em Crianças de 8 a 12 Anos (Monografia). Novo Hamburgo: Centro Universitário Feevale 2002, 46p.

2.Freire HBG. Equoterapia Teoria e Técnica: Uma Experiência com Crianças Autistas. São Paulo: Vetor, 1999, 7619p.

3.Associação Nacional de Equoterapia - ANDE/BRASIL. Fundamentos Básicos sobre Equoterapia. In: Congresso Brasileiro de Equoterapia. Coletânea de Trabalhos. Brasília: ANDE/BRASIL, 1999, p.13-6.

4.Cailliet R. Escoliose diagnóstico e tratamento. São Paulo: Manole, 1979, p.17-54.
5.Kisner C, Colby LA. Exercícios terapêuticos: fundamentos e técnicas. $3^{a}$. ed. São Paulo: Manole, 1998, 746p.

6.Cunningham B. The effect of hippotherapy on functional outcomes for children with disabilities: a pilot study. Pediatr Phys Ther 2009;21:137-8.

http://dx.doi.org/10.1097/PEP.0b013e318197a60d

7.Schwesig R, Neumann S, Richter D, Kauert R, Becker S, Esperer HD, et al. Impact of therapeutic riding on gait and posture regulation. Sportverletz Sportschaden 2009;23:84-94.

http://dx.doi.org/10.1055/s-0028-1109465

8.Tauffkirchen E. Hippotherapy--a supplementary treatment for motion disturbance caused by cerebral palsy. Padiatr Padol 1978;13:405-11.

9.Murphy D, Kahn-D’Angelo L, Gleason J. The effect of hippotherapy on functional outcomes for children with disabilities: a pilot study. Pediatr Phys Ther 2008;20:264-70.

http://dx.doi.org/10.1097/PEP.0b013e31818256cd

10.Janura M, Peham C, Dvorakova T, Elfmark M. An assessment of the pressure distribution exerted by a rider on the back of a horse during hippotherapy. Hum Mov Sci 2009;28:387-93.

http://dx.doi.org/10.1016/j.humov.2009.04.001

11.Nareklishvili TM. Dynamics of hip joint biomechanics in patients with coxarthrosis at the time of hippotherapy. Georgian Med News 2008;155:26-31. 12.Hamill D, Washington KA, White OR. The effect of hippotherapy on postural control in sitting for children with cerebral palsy. Phys Occup Ther Pediatr 2007;27:23-42.

http://dx.doi.org/10.1080/J006v27n04 03

http://dx.doi.org/10.1300/J006v27n04_03

13.Snider RK. Tratamento das Doenças do Sistema Musculoesquelético. São Paulo: Manole, 2000, 686p.

14.Behrman RE, Vaughan VC. Tratado de Pediatria. 13a. ed. Rio de Janeiro: Guanabara koogan, 2002, 2353p.

15.Bricot B. Posturologia. 2a ed. Sáo Paulo: Ícone, 2001, 270p.

16. Oliver J. Cuidados com as costas. São Paulo: Manole, 1999, 162p.

17.Carriel MLS, Gabriel MRS, Petit JD. Fisioterapia em Traumatologia, Ortopedia e Reumatologia. Rio de Janeiro: Revinter, 2001, 402p.

18. Citterio D. A hipoterapia na recuperação da pessoa portadora de deficiência e as atividades pré-esportivas. In: Congresso Brasileiro de Equoterapia. Anais. São Paulo: ANDE/BRASIL, 1999, p.33-4.

19.Silveira L. O Cavalo para a Equoterapia. In: Equoterapia: Princípios e fundamentos básicos aplicados à saúde e à educação. Resumos. 11ª . ed., curso básico de Equoterapia. Porto Alegre, junho, 2006.

20.Silva CH. Equoterapia para cegos: teoria e técnica de atendimento. Campo Grande: UCDB, 2004. 248p.

21.Engel B. Indicaçôes e Contra indicaçôes para a equoterapia; A Terapia Ocupacional Equestre, Fisioterapia ou Terapia. In: Equoterapia: Princípios e fundamentos básicos aplicados á saúde e á educação. Resumos. $11^{\mathrm{a}}$. ed., Curso básico de Equoterapia. Porto Alegre, 2006, s/p.

22.Garrigue R. A prática de Equoterapia. In: Congresso Brasileiro de Equterapia, Coletânea de Trabalhos. Brasília: ANDE/BRASIL, 1999, p.19-24.

23.Lima FS. A influência de um programa de hipoterapia na alteraçấo postural de indivíduos com paralisia cerebral. Revista de Equoterapia ANDE/BRASIL: Encontro entre dois Amigos 2005;12:26-30.

24.Grazziotin P. A Equoterapia como recurso terapêutico nas alteraçôes posturais - (Cifose Dorsal) (Monografia). Porto Alegre: Colégio Brasileiro de Estudos Sistêmicos; 2004, 56p. 